\title{
Efficacy of artemether-lumefantrine and artesunate- amodiaquine for treating uncomplicated falciparum malaria in children
}

\author{
Tri Faranita, Ayodhia Pitaloka Pasaribu, Muhammad Ali, Munar Lubis, Syahril Pasaribu
}

\begin{abstract}
Background Artesunate-amodiaquine (ASAQ) has been used as a first-line treatment for uncomplicated falciparum malaria in Indonesia since 2004. Its efficacy depends on amodiaquine resistance of the infecting parasites. Artemether-lumefantrine (AL) has been shown to be highly efficacious in treating uncomplicated falciparum malaria in several countries. However, there have been few studies on these anti-malarial medications in Indonesia.

Objective To compare the efficacy of AL to ASAQ for treating uncomplicated falciparum malaria in children.

Methods An open, randomized, controlled trial was conducted in school-aged children in the Mandailing Natal Regency, North Sumatera Province, Indonesia, from October to December 2010. A total of 280 pediatric, uncomplicated falciparum malaria patients were randomly assigned to receive either AL or ASAQ for 3 days. Participants were followed-up on days 1, 2, 3, 7, 14, 28 and 42 following the first medication dose. The outcomes noted were adequate clinical and parasitological response (ACPR), parasite reduction, parasite clearance time, fever clearance time and adverse events. Analysis was based on intention-to-treat.

Results In this study, ACPRs on day 42 were $86.4 \%$ and $90.7 \%$ for the ASAQ and AL groups, respectively $(\mathrm{P}=0.260)$. On days 7 and 14, the AL group had higher cure rates than that of the ASAQ group $(\mathrm{P}<0.05)$. Early treatment failure, late treatment failure and parasitological failure for both groups were similar. We also found faster parasite clearance time and higher parasite reduction in the AL group than in the ASAQ group. However, fever clearance time was shorter in the ASAQ group. The incidence of adverse events such as nausea, vomiting, malaise, and pruritus were similar between the two groups $(\mathrm{P}=0.441)$.

Conclusion AL had higher efficacy than ASAQ for the treatment
\end{abstract}

of uncomplicated falciparum malaria in children.

[Paediatr Indones. 2012;52:260-6].

Keywords: artemether-lumefantrine, artesunateamodiaquine, uncomplicated falciparum malaria

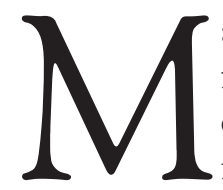
alaria remains a major health problem for children and adults in tropical areas of the world. ${ }^{1,2}$ In Indonesia, 411,000 malarial cases were reported in 2008, with 788 deaths in that year. Plasmodium falciparum infection caused $46 \%$ of these deaths. ${ }^{3}$

Most of the severe morbidity and mortality in malaria is caused by Plasmodium falciparum. ${ }^{4}$ To prevent the progression to severe disease and

From the Department of Child Health, University of Sumatera Utara Medical School, H. Adam Malik Hospital, Medan, Indonesia.

Reprint requests to: Tri Faranita, University of Sumatera Utara Medical School, H. Adam Malik Hospital, Jl. Bunga Lau No. 17, Medan 20136, Indonesia. Tel. +62-61-8361721, +62-61-8365663, Fax. +62-61-8361721.

E-mail:faranita.md@gmail.com

This study was presented at the Pediatric National Congress XV, Manado, 11 - 14 July 2011. 
additional morbidities associated with malaria, it is necessary to determine an effective therapy for uncomplicated falciparum malaria. ${ }^{5}$

In 2004, Indonesia implemented the use of artesunate and amodiaquine (ASAQ) in combination as the national, first-line treatment for uncomplicated falciparum malaria, after a data review on chloroquine efficacy revealed widespread chloroquine resistance throughout the country. ${ }^{6}$ Resistance to amodiaquine has been reported in Africa and Papua New Guinea. ${ }^{7,8}$

The combination of artemether and lumefantrine (AL) has been reported to be highly effective and well-tolerated in several African studies. 9,10 However, there has been limited information on the efficacy of these drugs in Indonesia. A previous study of this combination for treating falciparum malaria, vivax malaria and mixed infection malaria in Papua, Indonesia suggested that it was highly effective in children and adults. ${ }^{11}$ The aim of this study was to compare the efficacy of artemether-lumefantrine to artesunate-amodiaquine for treating uncomplicated falciparum malaria in children.

\section{Methods}

This randomized, open-label, controlled trial was conducted between October to December 2010 with subjects 12 elementary schools, the Panyabungan Malaria Centre and the outpatient clinic at the Panyabungan District Hospital, North Sumatera, Indonesia.

Subjects were children aged 6-18 years with uncomplicated falciparum malaria. Informed consent was obtained from their parents or guardians. Exclusion criteria were as follows: symptoms and/or signs of severe malaria, severe malnutrition, mixed malarial infections, known allergies to the study medications, vomiting after two dosing attempts, intake of any prior anti-malarial drug or withdrawal of consent.

Potential participants were medically screened. After obtaining capillary blood samples, thick and thin blood films were microscopically examined for the presence of malaria parasites. Body weight and body height were recorded. Nutritional status was assessed using weight-for-height chart CDC 2000. ${ }^{12}$
After enrollment, patients were randomly assigned to receive either artemether-lumefantrine or artesunate-amodiaquine. Medications were administered according to weight-based guidelines. The ASAQ group received a 3-day regimen of artesunate at $4 \mathrm{mg} / \mathrm{kg}$ orally combined with amodiaquine at $10 \mathrm{mg} / \mathrm{kg}$ once daily. Artemetherlumefantrine was administered twice daily as a three-day, six-dose regimen according to body weight [5 - <15 kg (1 tablet), $15-<25 \mathrm{~kg}$ (2 tablets), $25-<35 \mathrm{~kg}$ (3 tablets), $\geq 35 \mathrm{~kg}$ (4 tablets)] in the AL group. All drug doses were administered in front of physicians or guardians. Full drug doses were readministered if the patient either spat out or vomited the medications within 30 minutes. Vomiting of readministered medications resulted in withdrawal of the participant from the study. All excluded participants were given quinine for 7 days as well as doxycycline for children older than 7 years of age.

Clinical and laboratory assessments were made on days $0,1,2,3,7,14,28$ and 42. Parents/guardians were encouraged to come to the clinic if their child felt sick. Study participants were visited at home by members of the study team if a subject was absent on a scheduled visit day.

Giemsa-stained blood films were read by experienced microscopists. Parasitaemia was quantified per 200 leukocytes on the thick film. Slide quality control was done by masked re-reading of $10 \%$ of the slides selected randomly.

Treatment outcomes were defined as adequate clinical and parasitological response (ACPR) on day 42 , reduction in parasite counts, parasite clearance time and fever clearance time. Drug tolerability and safety were assessed clinically. An adverse event was defined as any undesirable medical occurrence in a patient during the study regardless of its relation to the treatment.

According to the WHO, ACPR is the absence of parasitaemia on day 28, without previously meeting criteria for early treatment failure (ETF), late treatment failure (LTF) or parasitological failure (PF). These criteria are defined as follows: ETF involves the presence of danger signs or complicated malaria or failure to adequately respond to therapy on days 0-3; LTF involves danger signs or complicated malaria or fever/history of fever in the previous 24 hours 
and parasitaemia on days 4-28 without previously meeting the criteria for ETF; and PF is asymptomatic parasitaemia on days 4-28 without previously meeting criteria for ETF or LTF.

Sample size was calculated by a non-inferiority study formula, resulting in 140 subjects per group. Data was analyzed using SPSS version 18.0 and Microsoft Excel 2003. The significance level was accepted as $\mathrm{P}<0.05$ with $95 \%$ confidence intervals (95\% CI).

Categorical variables were compared using the Chi square test. Independent t-test was used to compare reduction in parasite counts, parasite clearance time and fever clearance time. This study was an intention-to-treat analysis.

\section{Results}

Of 963 children screened for malarial infections, 482 children were infected and 202 children did not meet the criteria for enrollment. Of the 202 children, 200 had taken other anti-malarial drugs and 2 had mixed malarial infections. Of the 280 subjects enrolled, 140 received AL and the other 140 received ASAQ (Table 1).

In the AL group, 1 subject stopped taking medications without clear explanation and 1 subject moved away. In the ASAQ group, 2 subjects experienced adverse events causing them to prematurely withdraw from the study (one child experienced an allergic reaction with red skin and itching and the other child vomited after re-administration of the study drugs). These two children were excluded and treated with quinine.

Of the 276 children who completed the study, only 128 children in the AL group and 126 children in the ASAQ group completed the full 42 days of the study as others were lost to follow-up (Figure 1).

The ACPRs on day 42 were $90.7 \%$ and $86.4 \%$ in the AL and ASAQ groups, respectively $(\mathrm{P}=0.260)$. Also, ETF, LTF and PF were similar in both groups. However, after the third day of observation, the mean reduction in parasite counts in the AL group (95.7\%, SD 13.96) was significantly higher than that of the ASAQ group (74.8\%, SD 21.25); $(\mathrm{P}=0.0001)$. Mean parasite clearance time was also significantly shorter

Table. 1. Baseline characteristics of subjects

\begin{tabular}{|c|c|c|c|c|}
\hline \multirow{2}{*}{$\begin{array}{l}\text { Characteristics } \\
\text { Sex, n (\%) }\end{array}$} & \multicolumn{2}{|c|}{$\begin{array}{c}\text { AL } \\
n=140\end{array}$} & \multicolumn{2}{|c|}{$\begin{array}{c}\text { ASAQ } \\
\mathrm{n}=140\end{array}$} \\
\hline & & & & \\
\hline Male & 77 & (55.0) & 63 & $(45.0)$ \\
\hline Female & 63 & $(45.0)$ & 77 & $(55.0)$ \\
\hline Mean age, years (SD) & 7.9 & $(1.34)$ & 8 & $(1.48)$ \\
\hline Mean weight, kg (SD) & 22.3 & $(4.41)$ & 22.2 & (3.91) \\
\hline Mean height, cm (SD) & 123.6 & $(6.84)$ & 124.2 & $(8.39)$ \\
\hline \multicolumn{5}{|l|}{ Nutritional status, n (\%) } \\
\hline Normoweight & 60 & $(42.9)$ & 75 & $(53.6)$ \\
\hline Mild malnutrition & 42 & $(30.0)$ & 36 & $(25.7)$ \\
\hline Moderate malnutrition & 7 & $(5.0)$ & 6 & $(4.3)$ \\
\hline Overweight & 31 & $(22.1)$ & 23 & $(16.4)$ \\
\hline 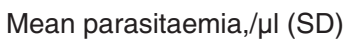 & 1071.5 & 294.89) & 1105.2 & 380.86) \\
\hline \multicolumn{5}{|l|}{ Symptoms, n (\%) } \\
\hline History of fever & 48 & (34.3) & 41 & $(29.3)$ \\
\hline Fever & 52 & $(37.1)$ & 37 & $(26.4)$ \\
\hline Pallor & 44 & (31.4) & 45 & (32.1) \\
\hline Weakness & 52 & $(37.1)$ & 51 & $(36.4)$ \\
\hline Headache & 41 & (29.3) & 24 & (17.1) \\
\hline Cough & 20 & (14.3) & 12 & $(8.6)$ \\
\hline Vomiting & 5 & (3.6) & 2 & (1.4) \\
\hline Diarrhea & 20 & (14.3) & 22 & (15.7) \\
\hline Hepatomegaly & 15 & (10.7) & 9 & $(6.4)$ \\
\hline Splenomegaly & 23 & $(16.4)$ & 17 & (12.1) \\
\hline
\end{tabular}

262 • Paediatr Indones, Vol. 52, No. 5, September 2012 
in the AL group [3.2 (SD 1.44) days] than in the ASAQ group [6.1 (SD 1.87) days]; $(\mathrm{P}=0.0001)$, but fever clearance time was significantly shorter in the ASAQ group $(\mathrm{P}=0.017)$ (Table 2).

During follow up (Table 3), cure rates on days 3, 28 and 42 were not significantly different between groups. However, on days 7 and 14, we found a significantly higher cure rate in the AL group than in ASAQ group $(\mathrm{P}<0.05)$.

During the study, we noted adverse events in both groups. In the AL group, 3 (2.1\%) subjects had nausea, 2 (1.4\%) had vomiting and 1 had $(0.7 \%)$ malaise. In the ASAQ group, 5 (3.6\%) had nausea, $6(4.3 \%)$ had vomiting, 3 (2.1\%) had malaise and 1 $(0.7 \%)$ had pruritus. Adverse events in the two groups were not significantly different $(\mathrm{P}=0.441)$.

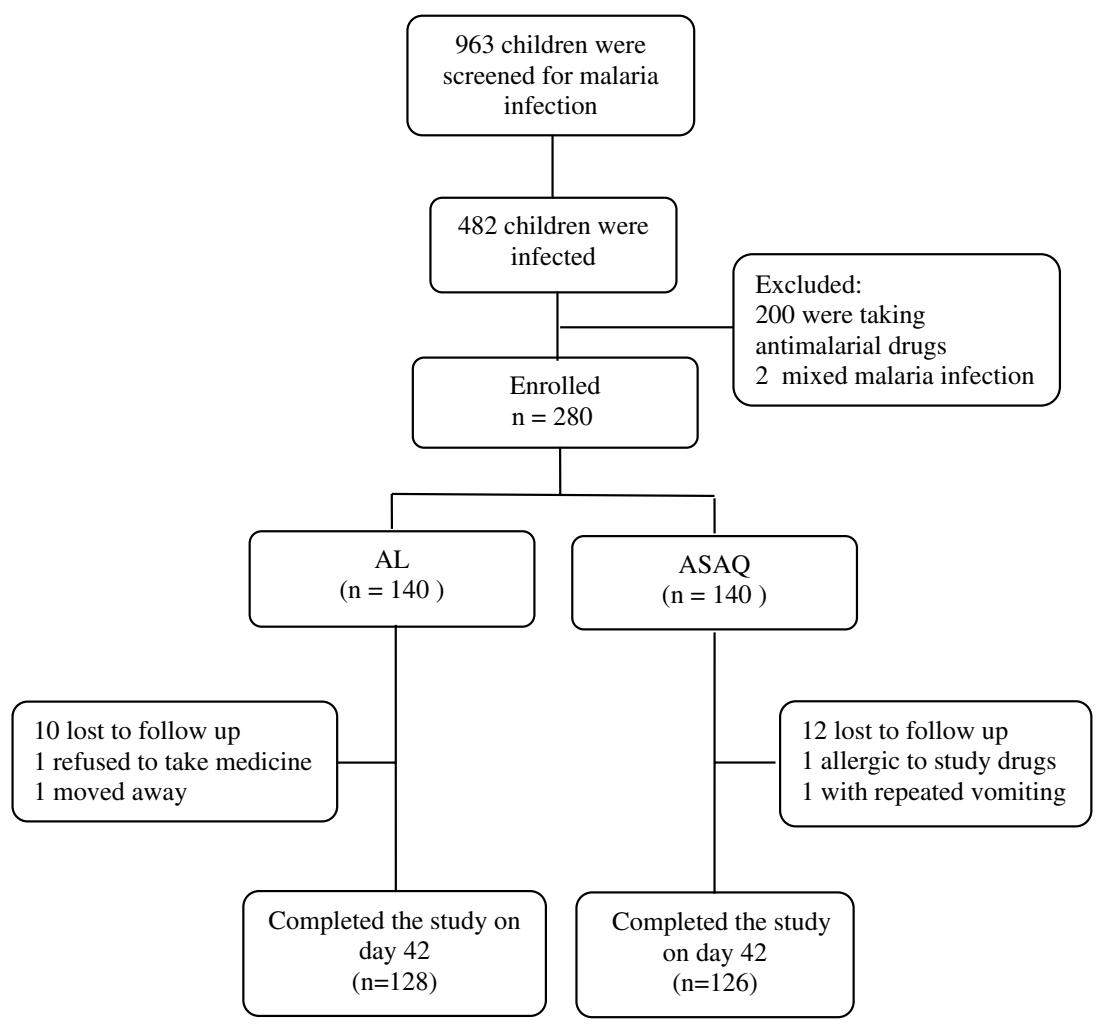

Figure 1. Study profile

Table 2. Treatment responses in both groups

\begin{tabular}{lccc}
\hline Treatment responses & $\mathrm{AL}$ & $\mathrm{ASAQ}$ & $\mathrm{P}$ \\
\hline Mean parasite clearance time, days (SD) & $\mathrm{n}=140$ & $\mathrm{n}=140$ & 0.0001 \\
Mean fever clearance time, days (SD) & $3.2(1.44)$ & $0.1(1.87)$ & 0.017 \\
ETF, $\mathrm{n}(\%)$ & $1.0(1.36)$ & $7(5.0)$ & 0.090 \\
LTF, $\mathrm{n}(\%)$ & $2(1.4)$ & $12(8.6)$ & 0.657 \\
PF, $\mathrm{n}(\%)$ & $10(7.1)$ & $0(0)$ & 0.316 \\
ACPR at day 42, $\mathrm{n}(\%)$ & $1(0.71)$ & $121(86.4)$ & 0.260 \\
Mean reduction in parasite count at day 3, \% (SD) & $127(90.7)$ & $74.8(21.25)$ & 0.0001 \\
\hline
\end{tabular}

ETF: early treatment failure; LFT: late treatment failure; PF: parasitological failure; ACPR: adequate clinical and parasitological response 
Tri Faranita et al: Artemether-lumefantrine and artesunate-amodiaquine for uncomplicated falciparum malaria

Table 3. Cure rate differences during follow-up

\begin{tabular}{cccc}
\hline $\begin{array}{c}\text { Cure rates } \\
\mathrm{n}(\%)\end{array}$ & $\begin{array}{c}\mathrm{AL} \\
(\mathrm{n}=140)\end{array}$ & $\begin{array}{c}\text { ASAQ } \\
(\mathrm{n}=140)\end{array}$ & $\mathrm{P}$ \\
\hline Day 3 & $138(98.57)$ & $133(95.0)$ & 0.090 \\
Day 7 & $136(97.14)$ & $127(90.71)$ & 0.024 \\
Day 14 & $136(97.14)$ & $124(88.57)$ & 0.005 \\
Day 28 & $127(90.71)$ & $121(86.42)$ & 0.260 \\
Day 42 & $127(90.71)$ & $121(86.42)$ & 0.260 \\
\hline
\end{tabular}

\section{Discussion}

In this open-label, randomized, controlled trial, AL had higher efficacy than ASAQ for treating children with uncomplicated malaria falciparum, similar to trials in Tanzania, ${ }^{13}$ and Cameroon. ${ }^{14}$

We gave a six-dose regimen of AL to one group of subjects. Evidence from previous studies showed that AL had better efficacy in a six-dose regimen than a four-dose regimen. ${ }^{15}$ Oral bioavailability of lumefantrine is highly dependent on its administration with fatty foods, ${ }^{5}$ as was reported in several studies from Ghana. ${ }^{16,17}$ We prepared fat-containing food or drink for participants before they took the medication.

ASAQ efficacy is influenced by amodiaquineresistance status. ${ }^{7,8}$ Several studies have suggested that resistance to amodiaquine occurs because of its structural similarity and mechanism of action to chloroquine. ${ }^{7,8,18}$ Azlin et al. reported that $32 \%$ of subjects with uncomplicated falciparum malaria had chloroquine resistance in 2004 in Mandailing Natal, North Sumatera. ${ }^{19}$ We found that the cure rate for the ASAQ group was $86.4 \%$, a decrease from a previous study in 2006. ${ }^{20}$

Shorter parasite clearance time occurred in the AL group than in the ASAQ group, in contrast to a Nigerian study in which both groups had similar parasite clearance times. ${ }^{21} \mathrm{We}$ also noted a higher treatment failure in ASAQ group, but not significantly different from the AL group. Both of these findings suggest that longer parasite clearance times may have been associated with higher risk for treatment failure as seen as in Senegal. 22

Rapid parasite clearance time has been associated with rapid fever clearance time. ${ }^{22}$ However, we found that while the parasite clearance time in the AL group was shorter, the fever clearance time was longer than that of the ASAQ group. The ongoing fever following parasite clearance suggests that the fever may be an adverse event from the treatment. ${ }^{23,24}$ Antipyretic use for fever treatment in malarial cases has been associated with longer parasite clearance time. ${ }^{25}$ Several of our subjects used antipyretics, but we did not evaluate the correlation between antipyretic use and parasite clearance time.

Adverse events in the ASAQ group were nausea, vomiting, malaise and pruritus. Severe adverse events occurred in two subjects, one with recurrent vomiting and one with an allergic reaction. Both children received second-line treatment medications. Other common adverse events such as headache or tinnitus ${ }^{25}$ from the drug combination were not observed in our subjects.

Adverse events in the AL group were nausea, vomiting and malaise. Studies in Uganda ${ }^{27}$ and Senegal ${ }^{23}$ reported temperature elevation, headache, stomachache and cough in patients taking AL. We did not observe these events in our subjects.

The objective of treating malaria with two or more blood schizontocidal drugs was to decelerate the development of resistance since the drugs have different mechanisms of action and parasitic biochemical targets. ${ }^{5}$ Artemisinin and its derivates have gametocidal effects. ${ }^{5,21} \mathrm{~A}$ limitation in our study was that we did not count the numbers of sexual parasites. Therefore, we could not determine the gametocyte clearance time in either group.

In conclusion, AL had higher efficacy than ASAQ for the treatment of uncomplicated falciparum malaria in children. We also found that both $\mathrm{AL}$ and ASAQ were safe for use in children.

\section{References}

1. Daly JP. Malaria. In: Gershon AA, Hotez PJ, Katz SL, editors. Krugman's infectious diseases of children. $11^{\text {th }}$ ed. Philadelphia: Mosby; 2004. p. 337-51. 
2. Greenwood BM, Bojang K, Whitty CJ, Targett GA. Malaria. Lancet. 2005;365:1487-98.

3. World Health Organization. Malaria in SEAR countries. [cited April 2010] Available from: http://www.searo.who.int/ en/Section10/Section21/Section340_4022.htm

4. Taylor TE, Strickland GT. Malaria. In: Strickland GT, editor. Hunter's tropical medicine and emerging infectious diseases. 8th ed. Philadelphia: Saunders; 2000. p. 614-41.

5. World Health Organization. Guidelines for the treatment of malaria. Switzerland: World Health Organization; 2006. P. 16-159

6. Departemen Kesehatan RI. Gebrak malaria pedoman tatalaksana kasus malaria di Indonesia. Jakarta: Departemen Kesehatan RI; 2009. p. 1-55.

7. Marfurt J, Mueller I, Sie A, Maku P, Goroti M, Reeder JC, et al. Low efficacy of amodiaquine or chloroquine plus sulfadoxine-pyrimethamine against Plasmodium falciparum and P. vivax malaria in Papua New Guinea. Am J Trop Med Hyg. 2007;77:947-54.

8. Mutabingwa TK, Anthony D, Heller A, Hallet R, Ahmed J, Drakeley C, et al. Amodiaquine alone, amodiaquine + sulfadoxine pyrimethamine, amodiaquine + artesunate, and artemether-lumefantrine for outpatient treatment of malaria in Tanzanian children: a four-arm randomized effectiveness trial. Lancet. 2005;365:1474-80.

9. Guthman JP, Cohuet S, Rigutto C, Fortes F, Saraiva N, Kiguli J, et al. Short report: high efficacy of two arteminin-based combinations (artesunate + amodiaquine and artemetherlumefantrine) in Caala, Central Angola. Am J Trop Med Hyg. 2006;75:143-5.

10. Dorsey G, Satedke S, Clark TD, Njama-Meya D, Nzarubara B, Maiteki-Sebuguzi C, et al. Combination therapy for uncomplicated falciparum malaria in Ugandan children. JAMA. 2007;297:2210-9.

11. Ratciff A, Siswantoro H, Kenangalem E, Maristela R, Wuwung RM, Laihad F, et al. Two fixed-dose artemisinin combinations for drug-resistant falciparum and vivax malaria in Papua, Indonesia: an open-label randomised comparison. Lancet. 2007;369:757-65.

12. Kuczmarski RJ, Ogden CL, Grummer-Strawn LM, Flegal KM, Guo SS, Wei R, et al. CDC growth charts: United States. Adv Data. 2000;314:1-27

13. Kabanywanyi AM, Mwita A, Sumari D, Mandike R, Mugittu K, Abdulla S. Efficacy and safety of artemisinin-based antimalarial in the treatment of uncomplicated malaria in Southern Tanzania. Malar J. 2007;6:146-50.

14. Whegang SY, Tahar R, Foumane VN, Soula G, Gwet $\mathrm{H}$, Thalabard J, et al. Efficacy of non-artemisinin and artemisinin-based combination therapies for uncomplicated falciparum malaria in Cameroon. Malar J. 2010;9:56-66.

15. Falade CO, Ogundele AO, Yusuf BO, Ademowo OG, Ladipo SM. High efficacy of two artemisinin-based combinations (artemether-lumefantrine and artesunate plus amodiaquine) for acute uncomplicated malaria in Ibadan, Nigeria. Trop Med Int Health. 2008;13:635-43.

16. Kobbe R, Klein P, Adjei S, Amemasor S, Thompson WN, Heidemann $\mathrm{H}$, et al. A randomized trial on effectiveness of artemether-lumefantrine versus artesunate plus amodiaquine for unsupervised treatment of uncomplicated Plasmodium falciparum malaria in Ghanaian children. Malar J. 2008;7:261-9.

17. Owusu-Agyei S, Asante KP, Owusu R, Adjuik M, AmengaEtego S, Dosoo DK, et al. An open label, randomized trial of artesunate+amodiaquine, artesunate + chlorproguanildapsone and artemether-lumefantrine for the treatment of uncomplicated malaria. PLoS ONE. 2008;3:e2530-7.

18. Swarthout TD, van der Broek IV, Kayembe G, Montgomery J, Pota H, Roper C. Artesunate + amodiaquine and artesunate + sulphadoxine-pyrimethamine for treatment of uncomplicated malaria in Democratic Republic of Congo: a clinical trial with determination of sulphadoxine and pyrimethamine-resistant haplotypes. Trop Med Int Health. 2006;11:1503-11.

19. Azlin E, Batubara I, Dalimunthe W, Siregar C, Lubis B, Lubis $\mathrm{M}$, et al. The effectiveness of chloroquine compared to fansidar in treating falciparum malaria. Pediatr Indones. 2004;44:17-20.

20. Pasaribu S, Pasaribu AP, Lubis CP. Combination of artesunateamodiaquine as a treatment for uncomplicated falciparum malaria in children. Pediatrics. 2008;121:S133.

21. Michael OS, Gbotosho GO, Folarin OA, Okuboyejo T, Sowunmi A, Oduola AM, et al. Early variations in Plasmodium falciparum dynamics in Nigerian children after treatment with two artemisinin-based combinations: implications on delayed parasite clearance. Malar J. 2010;9:335-43.

22. Sowunmi A, Adewoye EO, Gbotsho GO, Happi CT, Sijuade A, et al. Factors contributing to delay in parasite clearance in uncomplicated falciparum malaria in children. Malar J. 2010;9:53-64.

23. Faye B, Ndiaye JL, Ndiaye D, Dieng Y, Faye O, Gaye O. Efficacy and tolerability of four antimalarial combinations in the treatment of uncomplicated Plasmodium falciparum malaria in Senegal. Malar J. 2007;6:80-8.

24. Falade C, Manyando C. Safety profile of coartem: the evidence base. Malar J. 2009;8:1-6. 
Tri Faranita et al: Artemether-lumefantrine and artesunate-amodiaquine for uncomplicated falciparum malaria

25. Meremikwu MM, Logan K, Garner P. Antipyretic measures for treating fever in malaria (review). Cochrane Database Syst Rev. 2009;1:1-15.

26. Silvana S. Efikasi monoterapi artesunate dengan gabungan artesunate-amodiakuin pada pengobatan malaria falsiparum tanpa komplikasi pada anak[tesis]. Medan: Universitas
Sumatera Utara, 2008.

27. Maiteki-Sebuguzi C, Jagannathan P, Yau VM, Clark TD, Njama-Meya D, Nzarubara B, et al. Safety and tolerability of combination antimalarial therapies for uncomplicated falciparum malaria in Ugandan children. Malar J. 2008; 7:10613. 